\title{
Caring for an infant with trisomy 18: A case study and guidelines
}

\author{
Deborah A. Bruns \\ Department of Educational Psychology and Special Education Southern Illinois University Carbondale, U.S.A.
}

Correspondence: Deborah A. Bruns. Address: Special Education Program, Department of Educational Psychology and Special Education, Southern Illinois University Carbondale, MC 4618, Carbondale, IL 62901, U.S.A.

Email: dabruns@siu.edu

Received: August 18, 2013

DOI : $10.5430 /$ cns.v2n1p30

Accepted: October 21, 2013

Online Published: November 1, 2013

URL: http://dx.doi.org/10.5430/cns.v2n1p30

\begin{abstract}
Much of the literature describes the prognosis for infants with full trisomy 18 as bleak. The case study offered here provides an overview of an infant with this diagnosis who lived for 88.5 days in a Level III neonatal intensive care unit. Care decisions (medical and basic care) and their outcomes are described along with implications for care for infants with a diagnosis often characterized as incompatible with life. The need for information about treatment options and collaboration among an infant's medical team is emphasized.
\end{abstract}

\section{Key words}

Trisomy 18, Medical decision making, Care needs, Interventions

\section{I ntroduction}

Reported prevalence rates for infants with full trisomy 18 (Edwards syndrome or trisomy 18, presence of an extra 18th chromosome in every cell) are approximately one in 4000-8500 live births ${ }^{[1-5]}$. Much of the literature describes the prognosis for infants with trisomy 18 as bleak with multiple medical complications and high mortality rates ${ }^{[2,6]}$. Yet, there are reports of survival and positive responses to medical interventions ${ }^{[4,7-10]}$. In addition, Janvier and colleagues ${ }^{[11]}$ found consensus that a child with trisomy 18 enriches parents' lives, "Most parents reported that their family was strengthened since the birth, and often the death, of a child with t13 or 18” (p. 297).

\section{Description of trisomy 18}

The syndrome was first described by Edwards and colleagues ${ }^{[12]}$. It is the second most common trisomy condition after Down syndrome. Infants with trisomy 18 present with a distinctive physical appearance including low-set ears, clenched hands, short neck and rocker-bottom feet ${ }^{[3,13]}$. Jones ${ }^{[3]}$ also notes cardiac anomalies such as ventricular septal defect (VSD), pulmonary hypertension, central apnea, and feeding difficulties including reflux in this population. Brain malformations such as microcephaly and Arnold-Chiari malformation can occur. Gastrointestinal conditions including esophageal atresia and malrotation of intestines may also occur. Kidney issues are also prevalent such as horseshoe shaped kidneys and double ureters. These conditions coupled with an often negative stance toward aggressive treatment often leads to early mortality for infants who survive labor and delivery and the immediate newborn period. 
Medical professionals involved in caring for infants with trisomy 18 do not receive training related to this clinical subgroup or the training may have only emphasized palliative care or comfort care over more active and aggressive forms of treatment (e.g., surgery to repair a VSD). Yet, as stated above, there are reports of positive interventions and a need to respect parent wishes for aggressive care when warranted. The case study offered here provides an overview of care decisions and their outcomes within a context of the implications of care for an infant with a diagnosis often characterized as incompatible with life.

The information below presents a combination of medical records and excerpts from a book Simon's mother wrote about her experiences. This book was intended to raise awareness of trisomy 18 and provide parents in similar circumstances with an in-depth description of medical decision-making.

\section{Case presentation}

Initial ultrasounds showed clenched hands and a cleft lip and additional markers for trisomy 18 were noted and discussed throughout the pregnancy. Simon's mother refused further testing to confirm the diagnosis. She had two healthy sons (ages 7 and 5) and a history of six miscarriages due to her husband's inverted X chromosome.

She noted the following about her son's birth,

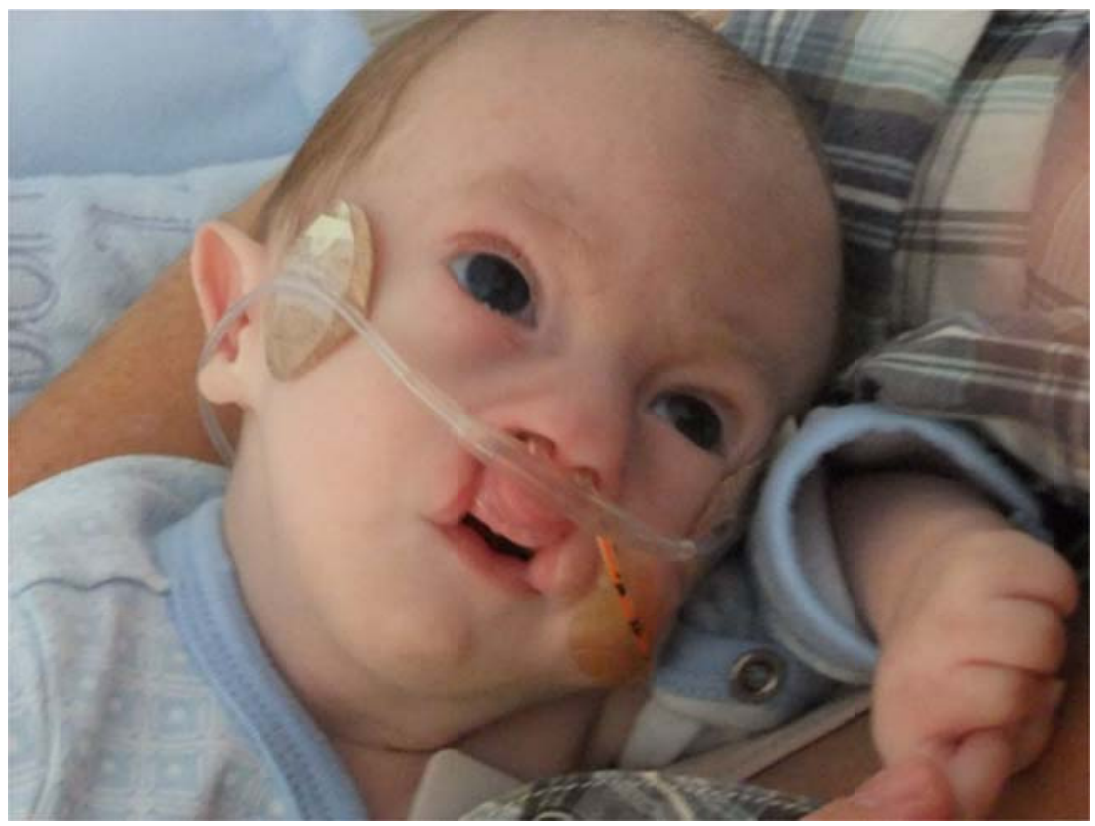

Figure 1. Simon

We arrived at the hospital at about 8:30 pm on September 6, 2010...Several hours after being induced, doctors noticed some deceleration of Simon's heart rate. We had made it clear that any signs of distress should lead to a c-section. The nurse called Dr. H. and he came in to talk about a c-section. When Dr. H. came in to talk about a c-section, he said, 'You know that I have concerns about Simon's condition, ${ }^{[14]}$ (p. 41-42).

In addition, a delivery room nurse mentioned how the heart rate of infants with trisomy 18 was not monitored during delivery per hospital policy. This non-monitoring approach is similar to findings in McGraw and Perlman's study of neonatologists and reinforces the recommendations against aggressive care ${ }^{[15]}$. 
Simon was born at 38 weeks gestation and 1900 grams. He presented with patent ductus arteriosus (PDA), VSD, coarctation and a bilateral cleft lip. Simon lived 88.5 days in a Level III neonatal intensive care unit (NICU) in a metropolitan Midwestern city (see Figure 1).

At the time of delivery, the following was noted in his chart:

"Infant with heart rate less than 100bpm and inadequate respiratory effort after delivery. Mouth suctioned and mask CPAP [continuous positive airway pressure] given without improvement in heart rate. Bag/mask breaths initiated and infant heart rate rose to $>100$ by 1 minute of life. Able to wean to mask CPAP subsequently, however infant continued to require $50 \%$ oxygen to maintain saturations $>88 \%$. Infant wrapped in warm blankets and introduced to mother and father. Infant transported to NICU in warmed isolette receiving mask CPAP.”

Unlike many infants with trisomy 18, Simon received medical interventions at birth. Aggressive care was due, in large part, to confirmation of his trisomy 18 diagnosis three days after birth via fluorescence in situ hybridization (FISH) testing.

\section{Medical decisions}

Simon's primary medical concern was due to his multiple cardiac anomalies (PDA, VSD and coarctation). His pediatric cardiologist offered the possibility of surgery once he stabilized and gained sufficient weight to withstand the procedure. Yet, no goal weight was ever established. The aspect that most concerned Simon's medical team about possible cardiac surgery was uncertainty about his short and long-term ability to breathe without ventilator support. Apnea episodes began on the third day of life. Central apnea is often associated with trisomy $18^{[3]}$ and factors into decision making for surgical candidacy as well as long-term survival. Simon's medical records do not indicate which type of apnea (central or obstructive). Regardless, it was significant that Simon was considered a surgical candidate with the trisomy 18 diagnosis ${ }^{[16]}$.

Simon was placed on prostaglandins (assist with dilation and contraction of smooth muscle including the heart) on his second day of life (prior to trisomy 18 diagnosis). A meeting was initiated by members of Simon's medical team in late September to discuss their withdrawal. Simon's parents were not made aware of this meeting or invited. In addition, one of Simon's nurses recommended that the issue be presented to the hospital's Ethics Committee. After review by the Ethics Committee, Simon's dosage was reduced by half.

By contrast, a care conference including his parents occurred in mid October to discuss echocardiogram results since Simon's PDA had largely closed and the coarctation was not as severe as initially thought. Significantly, Simon's pediatric cardiologist noted “in my 25-plus years of practice, I don’t remember seeing it happen” ${ }^{[14]}$ (p. 84). The same doctor also stated that his experience with Simon “...has literally changed my clinical approach in treating babies with these kinds of chromosomal conditions".

Yet, other concerns remained. A day after Simon's one month birthday, he experienced several central apnea episodes. His mother described the following,

“ $\mathrm{N}$, his nurse during the shift, said 'he's not responding'...Simon did self-recover, but this time, more slowly. I asked why N didn't use the oxygen mask. She said, 'on his chart it says 'Do Not Resuscitate”. In her opinion, that meant no bag and mask. I said, 'we’ve authorized the bag and mask. We only said 'no' to CPR”. ${ }^{[14]}$ (p. 78)

Parent agreement and permission is necessary for activation of a DNR order. The decision for a DNR for an infant with trisomy 18 should dependent on the severity of pressing medical issues rather than a recommendation due to the diagnosis. Parents must also be fully informed of the scope of a DNR and of their right to ask for its placement as well as removal from their infant's medical chart. The third, and final, care conference was conducted in mid November. Importantly, all 
care conferences were initiated by L, one of Simon's primary nurses. She took her request to the Medical Director who remarked "we don't do care conferences on terminal kids". In response, L stated "They are the ones who need care conferences most” ${ }^{[14]}$ (p. 75). The team met to discuss the DNR due to Simon's increasing oxygen needs and deteriorating cardiac status. The recommendation was for no bag and mask ventilation during central apnea episodes. Free flow oxygen would be permitted.

This care conference also addressed comfort care including administration of morphine. During Simon's last 24 hours of life, he was given Lorazepam twice for agitation after his parents turned down offers of morphine,

“[Nurse] J asked if I would consider giving Simon morphine...’'No morphine” I said...Instead we were offered a sedative, Lorazepam, which slows brain activity and encourages relaxation. We were assured that this medicine would not have an impact on his damaged heart...I still question my decision to allow Simon to receive this medicine” ${ }^{[14]}$ (p. 112).

Anecdotally, parents with infants with trisomy 18 have reported that morphine aids in pain management but can lead to respiratory distress due to infants' already comprised respiratory status. Simon's mother also shared how M, a primary nurse, checked in a medical textbook and found that Lorazepam is contraindicated for infants with apnea but was still given to Simon.

\section{Associated basic care needs}

In addition to pressing medical needs, Simon experienced feeding difficulties common to infants with trisomy $18^{[3]}$. At the outset, Simon's mother recounted how a nurse told her that some parents don't feed their trisomy babies. Simon's medical records indicated offering "comfort feeds" (drops of sucrose water) shortly after he was born rather than nutrient-rich feedings via gavage feeds.

Simon's mother pumped and stored breast milk for her son. During Simon's third week of life, L, one of Simon's primary nurses asked permission to put small amounts of breast milk in his nasogastric (NG) tube. Breast milk was offered via syringe for approximately the next two weeks and, when Simon was stable, by bottle as well. In addition, after discussion with the medical team, agreement was reached that Simon be given opportunities to nurse.

Oral feeds were largely successful along with NG feedings to ensure his daily caloric needs were met. Yet, Simon experienced some instances of reflux which is often noted in infants and older children with trisomy $18^{[17]}$. Nurses suggested thickening his formula with rice cereal. This was effective for a time but Simon aspirated on day 60 and was moved to total parenteral nutrition (TPN) feeds for approximately 48 hours along with sucrose water when agitated. It is important to note that a swallow study was not performed and no further evaluation was done after an initial x-ray. After this time period, breast milk mixed with rice cereal and formula via NG tube was reinstated. There were no oral feeds offered from this point on until Simon's passing.

\section{I mplications}

Simon's care draws attention to the need to provide care based on the individual infant, not his or her diagnosis. The points below are suggested as guidelines to inform provision of care to infants with trisomy 18 and their families:

- Review literature on trisomy 18. As this case study demonstrates, an infant may present with common medical conditions associated with the syndrome but his or her course will vary. It is vital to be knowledgeable of treatment options and unit or hospital policy on treatment. 
- Develop a unit-specific care map for parents with an infant with trisomy 18. The care map should encourage collaboration across nursing staff and staff from other medical disciplines for both day-to-day and long term care $^{[1,9,18]}$.

- Awareness of medications and associated side effects and contraindications for infants with trisomy 18 is warranted. Available literature provides limited specific recommendations since studies typically do not investigate pharmacological interventions ${ }^{[1]}$. Anecdotal data indicates a range of infant reactions to medications for cardiac and respiratory conditions. Provision of respiratory support should also be infant specific with discussions about its reduction and removal such as ventilator support. For infants who leave the neonatal unit, parents must be taught the necessary skills to operate and maintain the equipment along with information about monitoring their infant (e.g., increased oxygen needs when sleeping due to central apnea).

- Feeding options should be offered based on the infant's overall condition and trisomy 18 specific considerations due to low muscle tone and airway difficulties, Even if TPN is needed, tastes of sucrose and/or breast milk should be explored especially when requested by an infant's parent. Simon's mother's experiences should be considered in terms of opportunities for her to provide breast milk for her son and the accompanying bonding time that afforded.

- Care must be taken when presenting a recommendation for a Do not resuscitate (DNR) order. In-depth discussion of non-treatment is beyond the scope of this paper but nursing staff should be sensitive to the potential for conflict between the medical team and parents. Presentation of objective information about the need for a DNR should be accompanied with a clear description of what interventions it does and does not permit to ensure informed decision-making. The ability for DNR status to be changed should also be discussed.

- Immunizations should be determined on an individual basis. As illustrated in the case study presented here, while immunizations are important for overall health, negative effects are possible especially when an infant has trisomy 18 associated respiratory and cardiac issues.

As a whole, these guidelines require the presentation of balanced and easy-to-understand information to parents. Straightforward information is essential for parents to fully understand their infant's most pressing needs and options to address them. It is also recommended that clinical nurses seek parent perspectives from interactions on their units and through social media such as the Trisomy 18 Mommies Facebook group (see Table 1 for additional resources).

Further, the care of infants with trisomy 18 requires various types of decision making as described here. A collaborative approach is of paramount importance along with openness among team members about the potential for aggressive intervention to address acute and chronic medical issues. While some interventions may not produce positive outcomes (e.g., long-term ventilator use after surgery), there should be a willingness to discuss all possible options. This perspective should also extend to a valuation of life. Whether the child lives an hour, a day, a week or several months or years after birth, nurses with both knowledge and compassion is the key. There are parents who opt for comfort care and those who request treatment be provided as if their infant did not have the full trisomy 18 diagnosis. Parent requests should be honored within the parameters discussed above with an emphasis on understanding is that parents will advocate for their infant. It is beyond the scope of this article to discuss ethical and moral implications of caring for this group of infants ${ }^{[19,20]}$ but providing a balanced view of the benefits and associated risks of treatment must be part of parental decision-making. Simon's mother summed up her thoughts about medical decisions in this way, "We would have to live with our decisions for the rest of our lives. The medical staff could walk out the hospital doors and go home to be with their families and forget about...Simon...” ${ }^{[14]}$ (p. 48-49).

Simon's daily care and medical decision making was an ongoing process where “...they [the nurses] continued to treat Simon and inform us softly and respectfully while honoring our wishes” ${ }^{[14]}$ (p. 106). Simon’s mother also specifically 
noted "we were...grateful for Simon's nurses who took notes and explained Simon's changing condition in terms we could grasp” ${ }^{[14]}$ (p. 96). Simon compelled his nurses and doctors to examine their perceptions and perspectives about a child considered "incompatible with life". It is hoped that sharing Simon's mother's words and experiences, along with relevant empirical studies, contributes to a heightened understanding and appreciation of Simon and infants like him with corresponding improvements in the provision of basic care and medical decision-making.

Table 1. Trisomy 18 resources

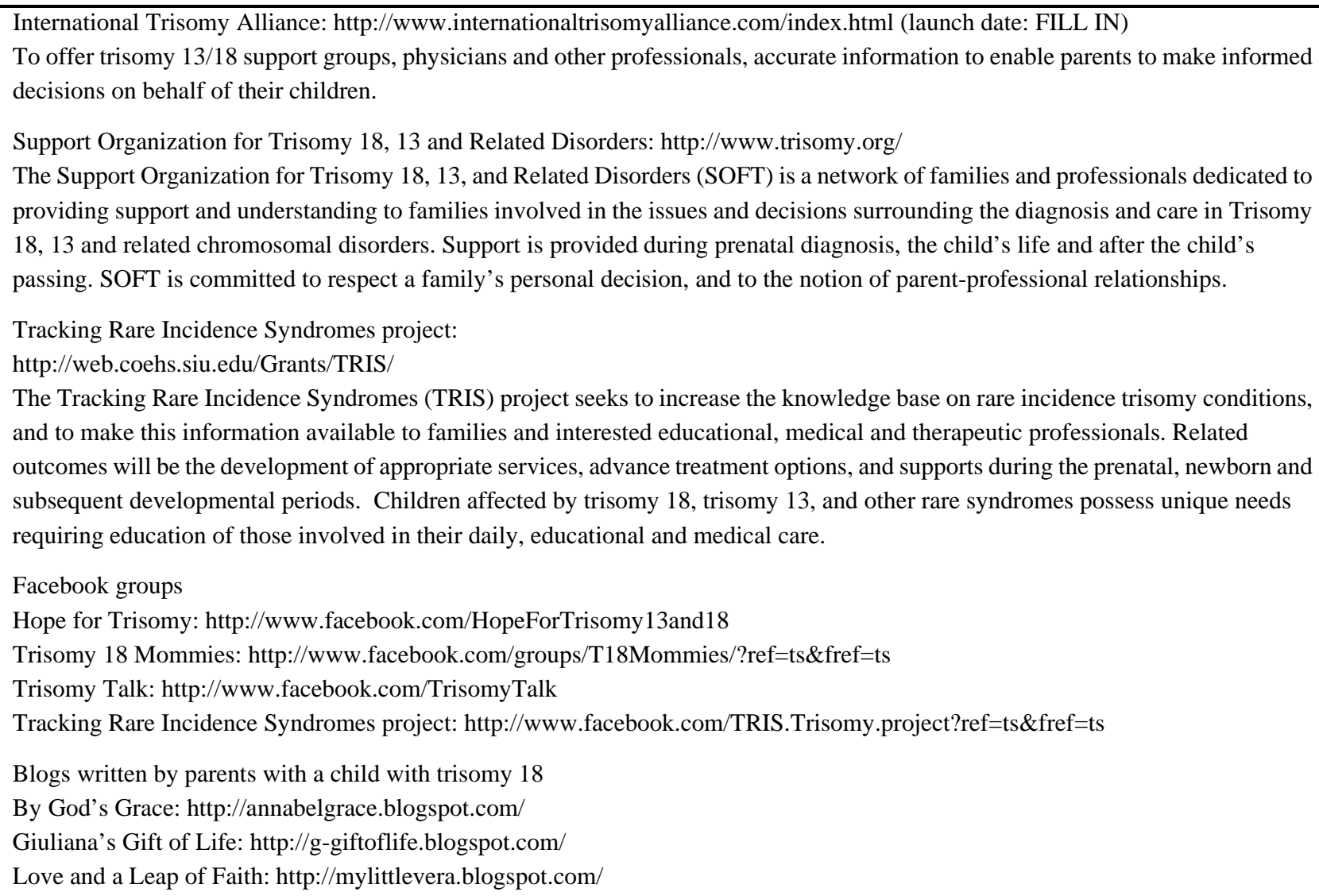

\section{Conclusion}

Individualized medical decision making for infants with trisomy 18 is necessary including an understanding of both facilitating and impeding factors to the treatment of common trisomy 18 medical conditions. Clinical nurses as well as nurse researchers should have an understanding of the breadth and depth of treatment needs of infants with trisomy 18 along with an appreciation of the value of infants such as Simon.

\section{Acknowledgement}

Sincere thanks to Sheryl Crosier for sharing Simon's story and her insights.

\section{References}

[1] Cereda A, Carey JC. The trisomy 18 syndrome. Orphanet J Rare Dis. 2012. PMid:23088440 http://dx.doi.org/10.1186/1750-1172-7-81

[2] Irving C, Richmond S, Wren C, Longster C, Embleton ND. Changes in fetal prevalence and outcome for trisomies 13 and 18: A population-based study over 23 years. J Maternal Fetal Neo Med. 2011; 24(1): 37-141. 
PMid:20384468 http://dx.doi.org/10.3109/14767051003758879

[3] Jones KL. Smith's recognizable patterns of human malformation (Sixth Edition). Philadelphia, PA: Elsevier Saunders; 2006.

[4] Kosho T, Kuniba H, Tanikawa Y, Hashimoto Y, Sakurai H. Natural history and parental experience of children with trisomy 18 based on a questionnaire given to a Japanese trisomy 18 parental support group. Am J Med Genet Part A. 2013; 161A: $1531-1542$. PMid:23720410 http://dx.doi.org/10.1002/ajmg.a.35990

[5] Vendola C, Canfield M, Daiger SP, Gambello M, Hashmi SS, King T, Noblin SJ, Waller DK, Hecht JT. Survival of Texas infants born with trisomies 21, 18 and 13. Am J Med Genet Part A. 2010; 152A: 360-366. PMid:20082470 http://dx.doi.org/10.1002/ajmg.a.33156

[6] Root S, Carey J. Survival in trisomy 18. Am J Med Genet Part A. 1994; 49: 170-174. PMid:8116664 http://dx.doi.org/10.1002/ajmg.1320490203

[7] Bruns DA. Neonatal experiences of newborns with full trisomy 18. Advances in Neonatal Care. 2010; 10(1): 25-31. PMid:20150778 http://dx.doi.org/10.1097/ANC.0b013e3181cbf54e

[8] Bruns DA, Campbell E. (accepted for publication). Twenty-two long-term survivors with full trisomy 18: Presenting and current medical conditions. Am J Med Genet Part A.

[9] Carey J. Perspectives on the care and management of infants with trisomy 18 and trisomy 13: Striving for balance. Curr Opin Pediatr; 2012. PMid:23044555 http://dx.doi.org/10.1097/MOP.0b013e3283595031

[10] Kosho T, Nakamura T, Kawame H, Baba A, Tamura M, Fukushima Y. Neonatal management of trisomy 18: Clinical details of 24 patients receiving intensive treatment. Am J Med Genet Part A. 2006; 140: 937-944. PMid:16528744 http://dx.doi.org/10.1002/ajmg.a.31175

[11] Janvier A, Farlow B, Wilfond B. The experience of families with children with trisomy 13 and 18 in social networks. Pediatrics: 2012; 130(2): 293-298. PMid:22826570 http://dx.doi.org/10.1542/peds.2012-0151

[12] Edwards JH, Harnden DG, Cameron AH, Crosse VM, Wolf OH. A new trisomic syndrome. Lancet: 1960; 275:787-790. http://dx.doi.org/10.1016/S0140-6736(60)90675-9

[13] Shaw J. Trisomy 18: A case study. Neonatal Network. 2008; 27(1): 33-41. PMid:18232589 http://dx.doi.org/10.1891/0730-0832.27.1.33

[14] Crosier S. I'm not a syndrome: My name is Simon. Tarpon Springs, FL: All Star Press; 2012.

[15] McGraw MP, Perlman JM. Attitudes of neonatologists toward delivery room management of confirmed trisomy 18: Potential factors influencing a changing dynamic. Pediatrics. 2008; 121(6): 1106 -1110. PMid:18519479 http://dx.doi.org/10.1542/peds.2007-1869

[16] Courtwright AM, Laughon MM, Doron MW. Length of life and treatment intensity in infants diagnosed prenatally or postnatally with congenital anomalies considered to be lethal. J Perinatol. 2011; 31: 387-391. PMid:21164425 http://dx.doi.org/10.1038/jp.2010.124

[17] Bruns DA, Springer SA. Feeding changes in children with trisomy 18: Longitudinal data on primary feeding method and reflux identification and treatment. Top Clinic Nutri: 2013[in press]; 28(4): 1-11.

[18] Carey J. Trisomy 18 and trisomy 13 syndromes. In S. B. Cassidy \& J. E. Allanson (Eds.), Management of genetic syndromes, 3rd edition: 2010. Hoboken, NJ: Wiley-Blackwell. http://dx.doi.org/10.1002/9780470893159.ch54

[19] Bruns DA. Erring on the side of life: Children with rare trisomy conditions, medical interventions and quality of life. J Genet Dis Genet Rep. 2013.

[20] Everett BJ, Albersheim SG. Ethical care for infants with conditions not curable with intensive care. J Clin Ethics. 2011; 22(1): 54-60. PMid:21595355 